\title{
Venous air embolism from blunt chest trauma
}

\author{
Cheryl R Laratta MD ${ }^{1}$, Lawrence Cheung MD FRCPC ${ }^{1,2}$
}

A 73-year-old woman was involved in a high-speed motor vehicle collision on a highway. When the ambulance arrived, the woman was found to be in pulseless electrical activity (PEA). Cardiopulmonary resuscitation was initiated and, although return of spontaneous circulation was initially achieved after $4 \mathrm{~min}$, the patient went into PEA arrest three additional times until arrival to the emergency department. After an initial chest $\mathrm{x}$-ray (Figure 1), a computed tomography (CT) scan of the chest revealed a large amount of air in the main pulmonary artery (Figures 2A and 2B, and Figure 3), with small amounts of air present in the right atrium, right ventricle, left and right brachiocephalic trunks (Figure 4), proximal superior vena cava and left subclavian vein. A left first rib fracture, bilateral pneumothoraces and left subclavian vein hematoma were present; trauma to the left subclavian vein was believed to be the source of the air embolism. Although hyperbaric oxygen and aspiration of the air under right heart catheterization were considered, the patient stabilized with mechanical ventilation and vasopressors. A CT scan of the chest $6 \mathrm{~h}$ later showed virtually complete resolution of the air in the vessels and heart, and the patient was discharged from hospital two months later.

\section{KEY LEARNING POINTS}

- Penetrating or blunt chest trauma can cause venous air embolism (1-3). Other causes include central line insertion, barotrauma during mechanical ventilation, bronchoscopic laser therapy, needle biopsy of the lung or other procedures $(1,3)$.

- CT scans may suggest the source of air entry in the setting of multiple injuries.

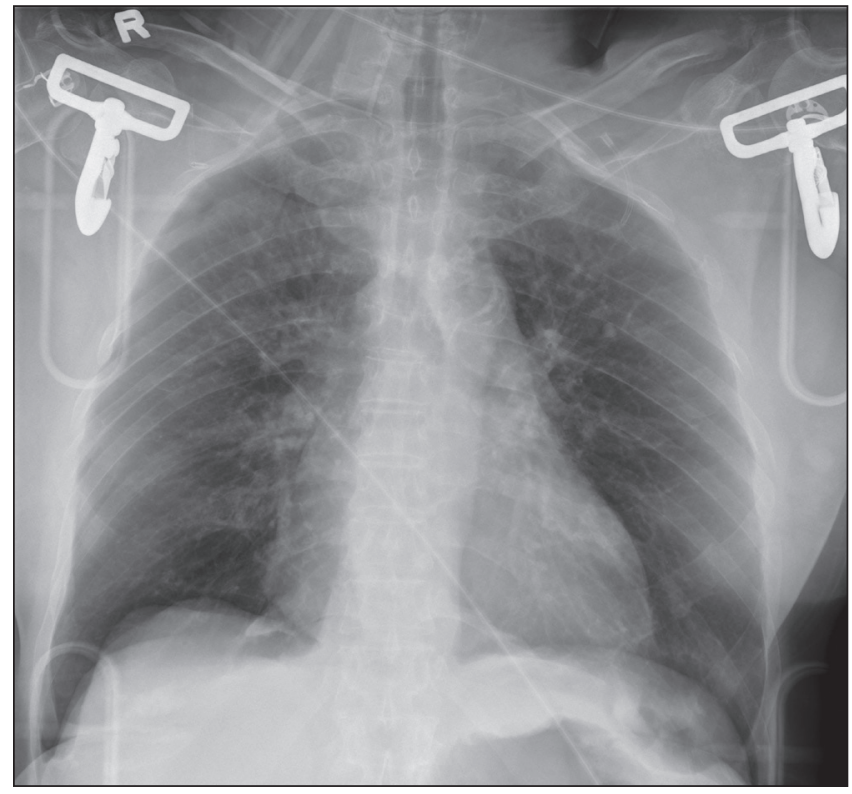

Figure 1) Initial anterior-posterior supine chest $x$-ray
- Venous air embolism may cause PEA by leading to transient 'air lock', pulmonary outflow tract obstruction, and diminished or absent cardiac output.

- Potential therapies include hyperbaric oxygen, aspiration of the air, left lateral decubitus head-down positioning and supportive care (3).

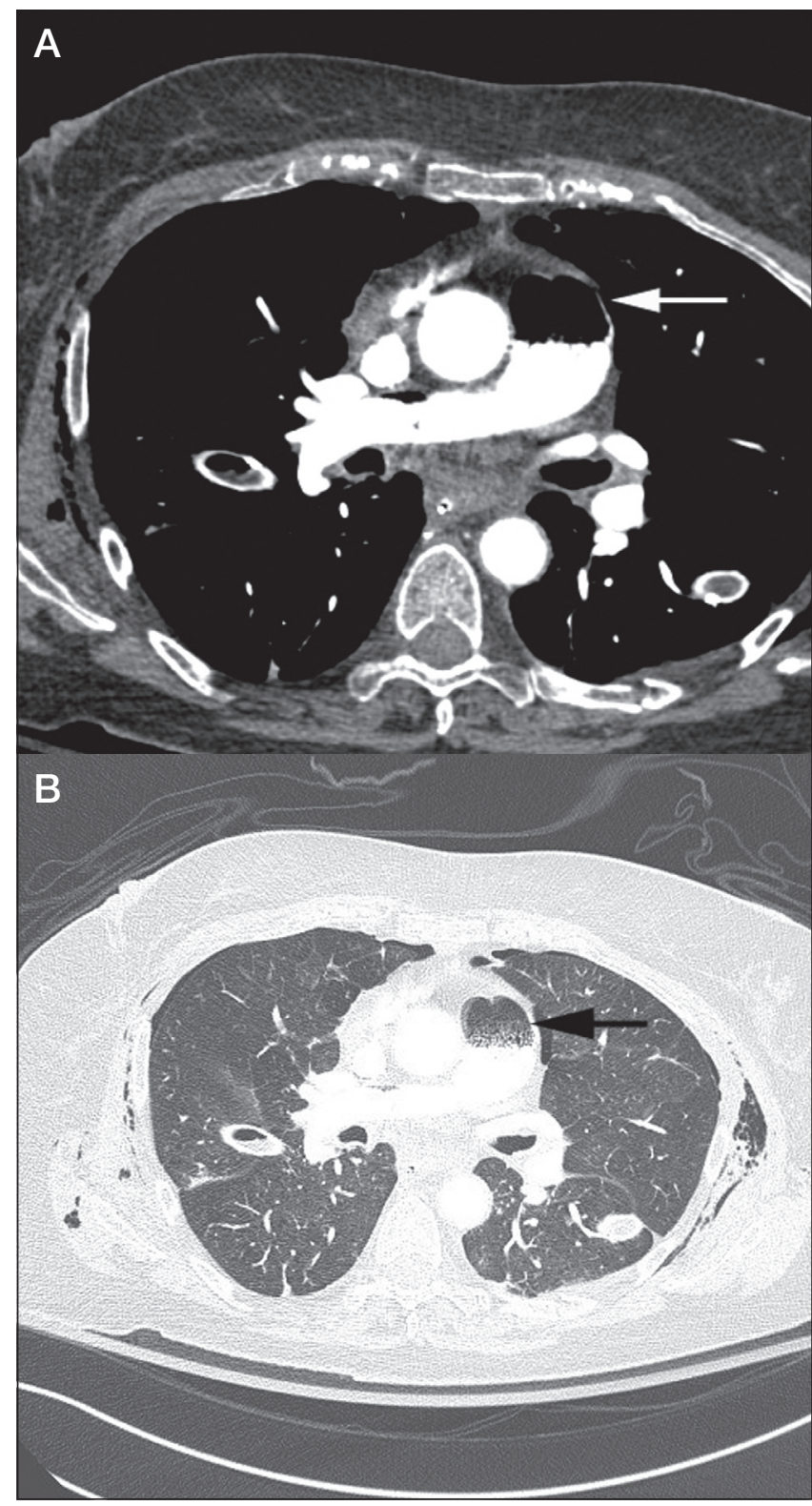

Figure 2) Axial chest computed tomography mediastinal windows (A) and lung windows (B) showing air in the main pulmonary artery (arrows)

${ }^{1}$ Division of Pulmonary Medicine, University of Alberta; ${ }^{2}$ Division of Critical Care Medicine, University of Alberta, Edmonton, Alberta Correspondence: Dr Lawrence Cheung, Department of Medicine, University of Alberta, 1135083 Avenue, Edmonton, Alberta T6G $2 \mathrm{G} 3$. Telephone 780-492-4039, fax 780-492-4483, e-mail lcheung@ualberta.ca 


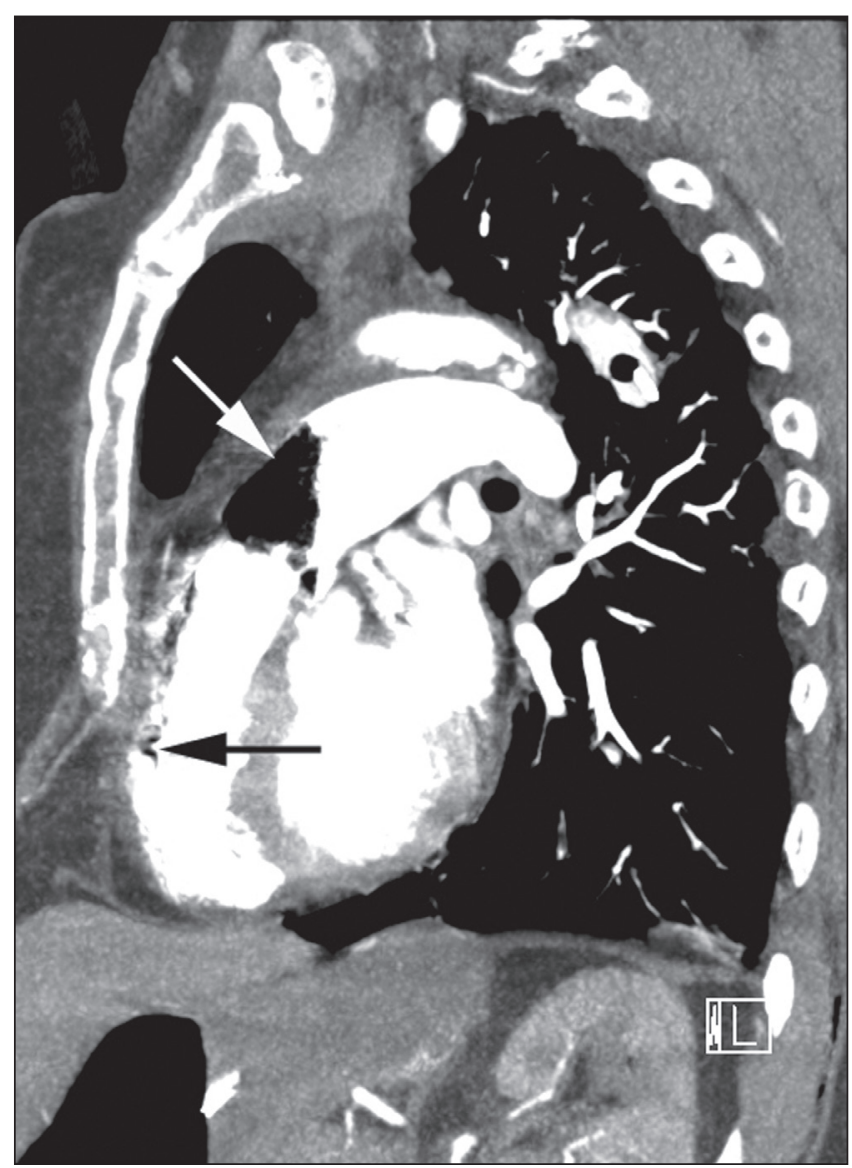

Figure 3) Sagittal chest computed tomography revealing air in the main pulmonary artery (white arrow) and right ventricle (black arrow)

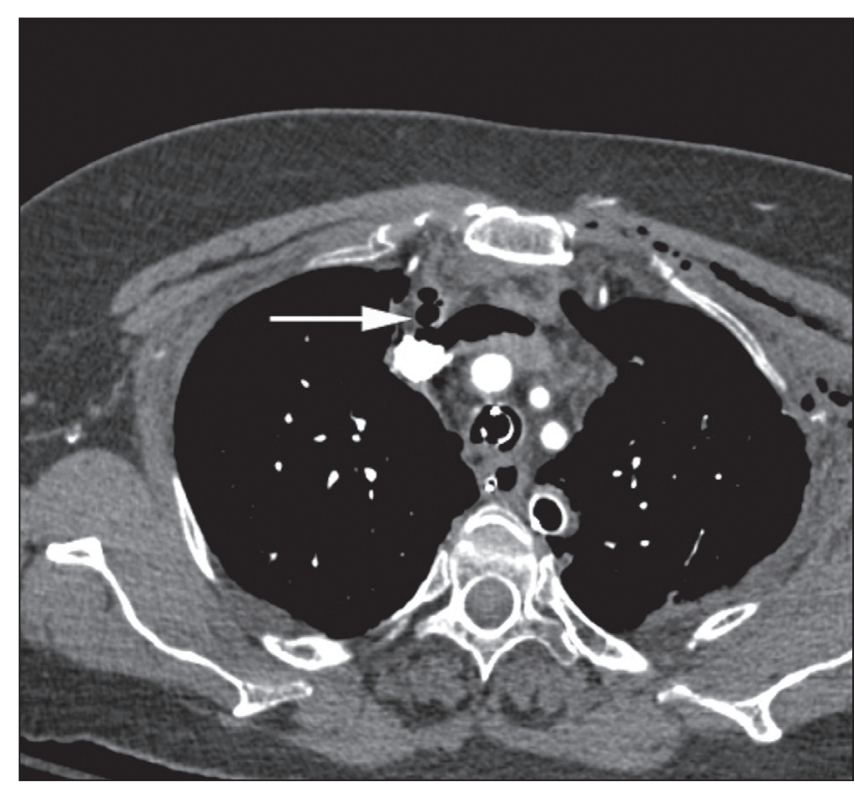

Figure 4) Axial chest computed tomography revealing air in the left and right brachiocephalic trunks (arrow)

\section{REFERENCES}

1. Thomas AN, Stephens GB. Air embolism: A cause of morbidity and death after penetrating chest trauma. J Trauma 1974;14:633-8.

2. Baker CC, Thomas AN, Turnkey DD. The role of emergency room thoracotomy in trauma. J Trauma 1990;20:848-55.

3. Ho A, Ling E. Systemic air embolism after lung trauma. Anesthesiology 1999;90:564-75.

The 'Images in Respiratory Medicine' section of the Canadian Respiratory Journal aims to highlight the importance of visual interpretation, whether physiological, radiological, bronchoscopic, surgical/thorascopic or histological, in the diagnosis of chest diseases. Submissions should exemplify a classic, particularly dramatic or intriguing presentation of a disease while offering an important educational message to the reader (insightful diagnostic pearls or differential diagnosis, etc). This section is not intended to be a vehicle for publication of case reports (see the Clinico-Pathologic Conferences for case-based leaning series). 


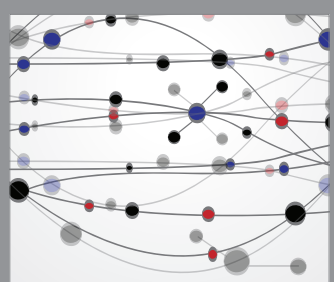

The Scientific World Journal
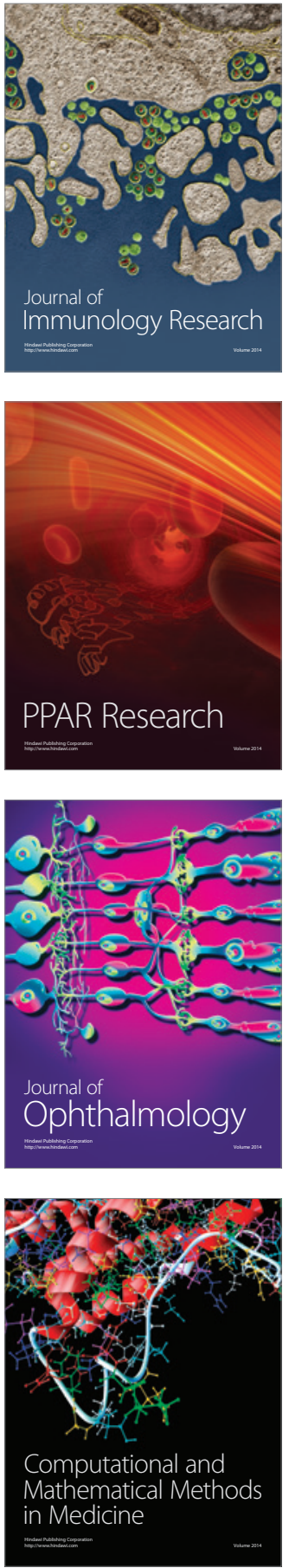

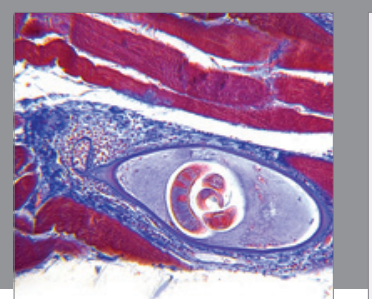

Gastroenterology Research and Practice

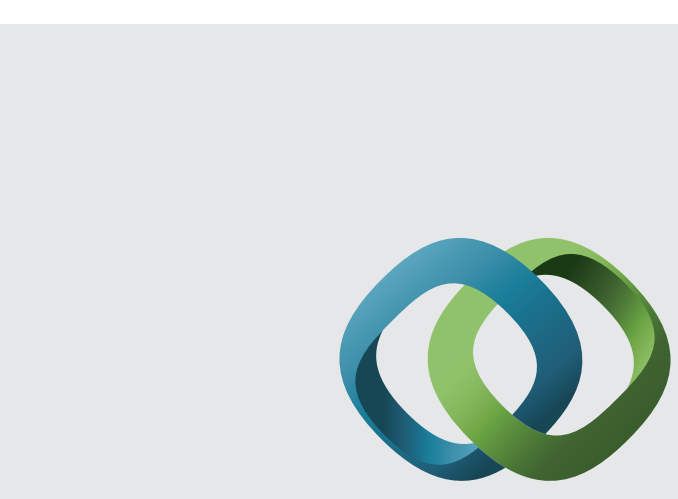

\section{Hindawi}

Submit your manuscripts at

http://www.hindawi.com
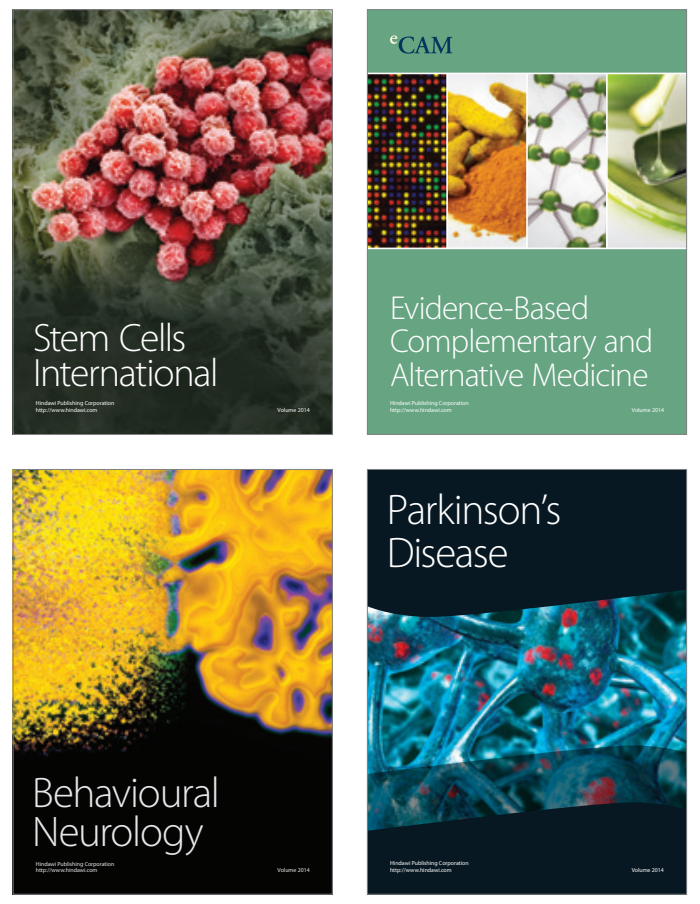
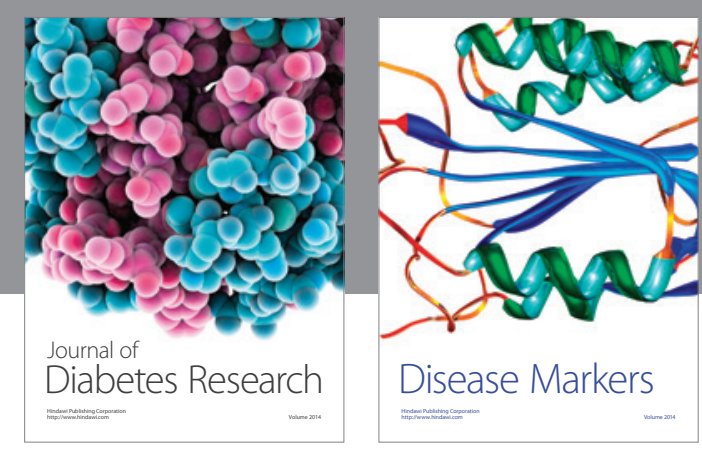

Disease Markers
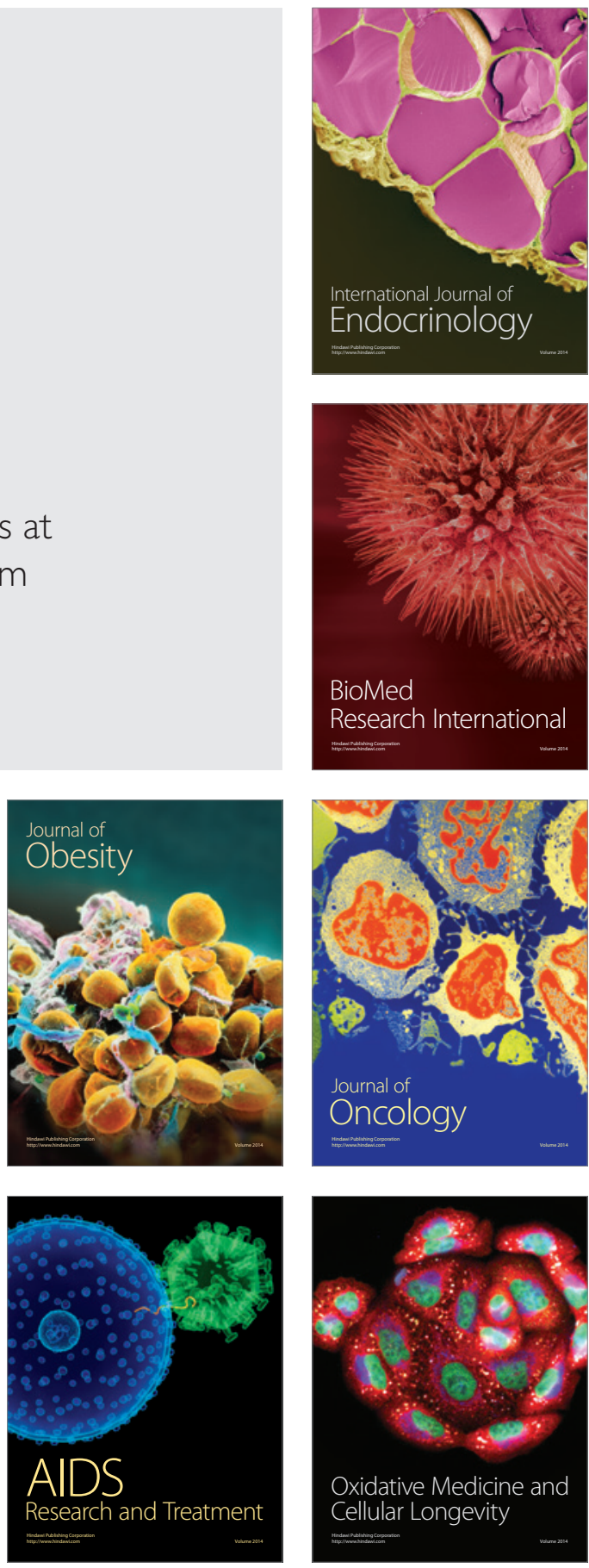